\title{
Titanium and vanadium oxynitride powders as pseudo-capacitive materials for electrochemical capacitors
}

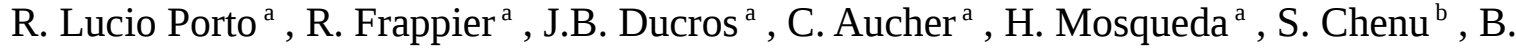 \\ Chavillon $^{\mathrm{b}}$, F. Tessier ${ }^{\mathrm{b}}$, F. Cheviré ${ }^{\mathrm{b}}$, T. Brousse ${ }^{\mathrm{a}, *}$

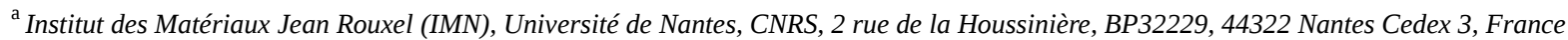 \\ ${ }^{\mathrm{b}}$ Sciences Chimiques de Rennes - équipe Verres et Céramiques, UMR CNRS 6226, 242 avenue du Général Leclerc, campus de Beaulieu, 35042 \\ Rennes Cedex, France \\ *E-mail address: Thierry.brousse@univ-nantes.fr
}

\begin{abstract}
TiO}_{\mathrm{x}} \mathrm{N}_{\mathrm{y}}$ and $\mathrm{VO}_{\mathrm{x}} \mathrm{N}_{\mathrm{y}}$ powders have been synthesized using oxide precursors and a conventional nitridation method. It enables to control of oxygen content and surface area. The electrochemical performances of the different powders have been investigated. A strong dependence on the surface area as well as on the nature of the oxynitride has been found. A typical value of $300 \mu \mathrm{F} \mathrm{cm}{ }^{-2}$ has been determined for $\mathrm{VO}_{x} \mathrm{~N}_{y}$ powders, while $\mathrm{TiO}_{\mathrm{x}} \mathrm{N}_{\mathrm{y}}$ powders only show $50 \mu \mathrm{F} \mathrm{cm}^{-2}$. In this last case it is believed that only double layer capacitance or weak redox reactions participate in charge storage mechanism while for vanadium based oxynitrides, a thin layer below the surface $(\approx 4 \AA)$ is involved in charge storage via faradic reactions. $\mathrm{VO}_{\mathrm{x}} \mathrm{N}_{\mathrm{y}}$ electrodes can be operated in different aqueous electrolytes, but only double layer capacitance is measured in neutral electrolytes. The highest capacitance values $\left(\approx 80 \mathrm{~F} \mathrm{~g}^{-1}\right)$ are measured in $\mathrm{KOH}$ and fair cycling ability is achieved when the electrochemical window is limited, thus avoiding oxidative potentials.
\end{abstract}

\section{Introduction}

Most of the commercially available electrochemical capacitors (ECs), also named supercapacitors, are using carbon materials as electrodes and store energy via a charge separation at the electrode/electrolyte interface. Even if $5-10 \%$ of the capacitance can be due to surface redox reactions on carbon, this class of ECs is named "electrochemical double layer capacitors". The capacity of such ECs is limited to $\sim 250 \mathrm{~F} \mathrm{~g}^{-1}$ in aqueous electrolytes for high surface area carbon materials [1]. To overcome this limitation, new types of ECs named "pseudo-capacitors" have been developed [2]. In this case, electrodes consist of metal oxides such as $\mathrm{RuO}_{2}[3,4]$ or $\mathrm{MnO}_{2}$ [5-8] for example and the high capacitance is due to the combination of double layer capacitance (minor contribution) and faradic surface reactions (major contribution). A tremendous amount of work has been published on $\mathrm{MnO}_{2}$ electrodes [9-11]. One of the main conclusions about this material is the lack of electronic conductivity compared to $\mathrm{RuO}_{2}$, which severely limits the power capability of such $\mathrm{MnO}_{2}$ based electrodes. In 1998, Conway opened the way for a new kind of electrode materials [12], namely molybdenum nitrides, which demonstrated quite interesting pseudocapacitive behavior in acidic electrolyte. This work was only followed by another paper from Roberson et al. [13]. The work initiated by Conway was recently revisited with other metal nitrides such as TiN [14,15] and VN [16-19], probably due to the attractive electronic conductivity of these compounds which enables them to compete with oxide based pseudocapacitive materials. Indeed, VN electrodes have demonstrated impressive capacitance values, up to $1340 \mathrm{~F} \mathrm{~g}^{-1}$ [16]. VN is also the topic of recent advanced studies in which original nanostructure involving coated nanotubes [20] or TiN/VN core/shell nanostructure [21] have been prepared and investigated as ECs electrodes. Molybdenum and niobium nitrides have also attracted new interest [22]. However, literature data on nitrides is limited to a few ten of papers and many points are still unclear, requiring further investigations.

An interesting point among all these studies on nitride based materials for ECs is the use of VN and TiN which are now already used as hard coating on different drilling and cutting tools. Unlike nitride coatings, the synthesis of powders from these two nitrides is quite difficult in the sense that it is tricky to monitor both the surface area and the oxygen content of the synthesized powder. In this communication, we propose to investigate the electrochemical performance of different vanadium and titanium oxynitride powders produced via simple conventional nitridation methods starting from corresponding oxides. The influence of the surface area and oxygen content will be investigated and possible explanations of their electrochemical behavior will be provided.

\section{Experimental}

\subsection{Synthesis of oxynitrides}

A summary of the synthesis conditions of the different powders is given in Tables 1 and 2. $\mathrm{TiO}_{2}$ Degussa P25 was used as a precursor for the preparation of the oxynitride $\mathrm{TiO}_{x} \mathrm{~N}_{\mathrm{y}}$ samples (TiN8 and TiN60), while oxynitride $\mathrm{VO}_{\mathrm{x}} \mathrm{N}_{\mathrm{y}}$ samples - VN25 - was obtained from a $\mathrm{VO}_{2}$ precursor which was synthesized by hydrothermal reaction: a mixture of $800 \mathrm{mg}$ of $\mathrm{V}_{2} \mathrm{O}_{5}$ (Aldrich 99\%), $6 \mathrm{ml}$ of ethylene glycol and $9 \mathrm{ml}$ of distilled water was poured in a Teflon TM acid 
digestion liner. The liner filled at $70 \%$ of its volume capacity was sealed in an autoclave and placed in an oven for $3 \mathrm{~h}$ at $190{ }^{\circ} \mathrm{C}$. Then, the product was allowed to cool down at room temperature. This synthesis yielded a pure $\mathrm{VO}_{2}$ precipitate which was taken out by discarding the supernatant liquid and was subsequently washed thoroughly with distilled water and ethanol. Then, the resulting powder was air dried in an oven at $100^{\circ} \mathrm{C} . \mathrm{VO}_{\mathrm{x}} \mathrm{N}_{\mathrm{y}}$ samples (VN3, VN26, VN28a, VN28b, and VN29) have been obtained using commercial $\mathrm{V}_{2} \mathrm{O}_{5}$ (Aldrich 99\%) as the precursor for ammonolysis reactions. Nitridation reactions were carried out in alumina boats placed inside an electric tubular furnace through which ammonia gas (air liquide-purity $>99.9 \%$ ) flowed with a rate of $10 \mathrm{l} \mathrm{h}^{-1}$. Prior to start, the reaction tube was flushed by $\mathrm{N}_{2}$ for $10 \mathrm{~min}$ to prevent air contamination The temperature was raised in the $600-1200{ }^{\circ} \mathrm{C}$ range at different heating rates (see Table 1). After the reaction, the furnace was switched off and the nitrided powders were allowed to cool to room temperature under ammonia until the temperature reached $100^{\circ} \mathrm{C}$. Below this temperature nitrogen atmosphere replaced ammonia [23]. All the powders are referenced according to their identified crystallographic phase and BET surface area, i.e. VN3 and TiN60 for examples, respectively for the first and last samples reported in Table 1.

Table 1 : Synthesis conditions of VN and TiN samples.

\begin{tabular}{lllll}
\hline Reference & $\begin{array}{l}\text { Heating rate } \\
\left({ }^{\circ} \mathrm{C} \mathrm{min}{ }^{-1}\right)\end{array}$ & $\begin{array}{l}\text { Nitridation } \\
\text { temperature }\left({ }^{\circ} \mathrm{C}\right)\end{array}$ & $\begin{array}{l}\text { Nitridation } \\
\text { time }(\mathrm{h})\end{array}$ & $\begin{array}{l}\text { Observed } \\
\text { phases }\end{array}$ \\
\hline VN3 & 8 & 1000 & 20 & $\mathrm{VN}$ \\
VN29 & 8 & 600 & 20 & $\mathrm{VN}$ \\
VN28a & 8 & 600 & 10 & $\mathrm{VN}$ \\
VN26 & 8 & 600 & 5 & $\mathrm{VN}$ \\
VN28b & 8 & 600 & 2 & $\mathrm{VN}$ \\
VN25 & 3 & 700 & 1 & $\mathrm{VN}$ \\
TiN8 & 4 & 1200 & 48 & $\mathrm{TiN}$ \\
TiN60 & 5 & 700 & 20 & $\mathrm{TiN}$ \\
\hline
\end{tabular}

\subsection{Material characterization}

A flowsorb II 2300 Micromeritics apparatus was used to determine the specific surface area of the powders by the single point method. Before measurement, the samples were outgassed under $\mathrm{He} / \mathrm{N}_{2}$ flow between $100{ }^{\circ} \mathrm{C}$ and $200{ }^{\circ} \mathrm{C}$ for $30 \mathrm{~min}$.

Nitrogen and oxygen contents were determined with a Leco® TC-600 analyzer using the inert gas fusion method. Nitrogen was measured as $\mathrm{N}_{2}$ by thermal conductivity and oxygen as $\mathrm{CO}_{2}$ by infrared detection. The apparatus was calibrated using Leco® standard oxides and $\mathrm{Si}_{2} \mathrm{~N}_{2} \mathrm{O}$. Chemical formulations were calculated by considering that samples contain only $\mathrm{M}, \mathrm{O}$ and $\mathrm{N}(\mathrm{M}=\mathrm{V}$, Ti).

XRD powder patterns were recorded using a Philips PW3710 diffractometer operating with $\mathrm{Cu}$ Ka radiation $(\lambda=1.5418 \AA)$. X'PERT softwares - Data Collector and Graphics, and Identify - were used, respectively, for pattern recording, analysis and phase matching. Scanning electron micrographs were taken with a Zeiss Merlin field effect gun microscope.

Table 2 : Oxygen and nitrogen contents, surface area of VN and TiN samples.

\begin{tabular}{lllll}
\hline Reference & Formula & Oxygen (wt \%) & Nitrogen (wt \%) & $\begin{array}{l}\text { Surface area } \\
\left(\mathrm{m}^{2} \mathrm{~g}^{-1}\right)\end{array}$ \\
\hline VN3 & $\mathrm{VO}_{0.04} \mathrm{~N}_{1.02}$ & 1.7 & 21.6 & 3 \\
VN29 & $\mathrm{VO}_{0.31} \mathrm{~N}_{0.89}$ & 7.3 & 18.2 & 29 \\
VN28a & $\mathrm{VO}_{0.33} \mathrm{~N}_{0.89}$ & 9.0 & 17.9 & 28 \\
VN26 & $\mathrm{VO}_{0.43} \mathrm{~N}_{0.83}$ & 9.9 & 16.7 & 26 \\
VN28b & $\mathrm{VO}_{0.56} \mathrm{~N}_{0.76}$ & 12.8 & 15.1 & 28 \\
VN25 & $\mathrm{VO}_{0.46} \mathrm{~N}_{0.85}$ & 10.5 & 16.9 & 35 \\
TiN8 & $\mathrm{TiO}_{0.08} \mathrm{~N}$ & 2.1 & 22.2 & 8 \\
TiN60 & $\mathrm{TiO}_{0.47} \mathrm{~N}_{0.97}$ & 11.0 & 19.2 & 60 \\
\hline
\end{tabular}




\subsection{Electrochemical characterization}

For electrochemical tests, the nitride based electrodes were prepared from a mixture of active material, carbon black (CB from Superior Graphite) and PTFE in a 75:15:10 weight proportion. The electrodes were prepared by mixing all components with ethanol and slow drying at $70{ }^{\circ} \mathrm{C}$. The paste thus obtained was cold rolled in $100 \mu \mathrm{m}$ thick films $(\approx 20$ $\mathrm{mg} \mathrm{cm}{ }^{-2}$ ) and pressed in a stainless steel grid at $1 \mathrm{GPa}$.

Electrochemical measurements were performed in a three-electrode cell, using a platinum grid as counter-electrode and $\mathrm{Hg} / \mathrm{HgO}$ as reference electrode. The electrolytes used were $1 \mathrm{M} \mathrm{KOH}, 0.5 \mathrm{M} \mathrm{H}_{2} \mathrm{SO}_{4}$ and $5 \mathrm{M} \mathrm{LiNO}_{3}$ provided by Alfa Aesar with at least $98 \%$ purity. The chemicals were used without further purification. Electrochemical measurements were controlled via a VMP 3 potentiostat-galvanostat (Biologic).

\section{Results}

\subsection{Materials synthesis and characterizations}

There are different methods reported in the literature for preparing VN or TiN powders. A closer look at the powders prepared for EC purposes highlights two main kinds of synthesis techniques. The first category of synthesis avoids oxide precursors and focuses on reacting chlorides or iodides with gaseous ammonia at different temperatures. For example, nanostructured $\mathrm{VN}$ powder was synthesized using a $\mathrm{VCl}_{4}$ precursor. The chloride was dissolved and stirred in anhydrous chloroform inside a glove box. The solution was then transferred to an Ar-filled glove bag where the dissolved chloride was reacted with anhydrous $\mathrm{NH}_{3}$ gas over solution for $8 \mathrm{~h}$ [16]. However, oxygen is always found in the resulting powders, together with other elements such as chlorine, which makes such synthesis difficult to monitor.

A second category of synthesis takes advantage of the large surface area of oxide precursors to prepared nitrides which always content various amounts of oxygen but do exhibit adequate crystallographic nitride phase. $\mathrm{VO}_{\mathrm{x}} \mathrm{N}_{\mathrm{y}}$ powders were synthesized by temperature programmed $\mathrm{NH}_{3}$ reduction of $\mathrm{V}_{2} \mathrm{O}_{5}[17,18]$. TiN/VN core-shell composites were also prepared by a two-step strategy involving coating of commercial TiN nanoparticles with $\mathrm{V}_{2} \mathrm{O}_{5} n \mathrm{H}_{2} \mathrm{O}$ sols followed by ammonia reduction [21]. For our synthesis we used either $\mathrm{V}_{2} \mathrm{O}_{5}$ or $\mathrm{VO}_{2}$ precursors in an ammoniac flow at various annealing temperatures. The resulting powders exhibit cubic VN $(F m-3 m)$ crystallographic phase with a cell parameter $\approx 0.429 \mathrm{~nm}$ (Fig. 1a). However, elemental analysis reveals the presence of noticeable amount of oxygen (Table 2) which can reach appreciable values (more than $50 \%$ of the nitrogen content), thus suggesting the synthesis of oxynitrides rather than pure nitrides. The oxygen amount is progressively removed by increasing the annealing temperature (Tables 1 and 2). This occurs at the expense of the surface area which strongly decreases when the annealing temperature increases. Indeed increasing the temperature from $600{ }^{\circ} \mathrm{C}$ up to $1000{ }^{\circ} \mathrm{C}$ while keeping the same annealing time leads to a decrease of the BET surface area from $29 \mathrm{~m}^{2} \mathrm{~g}^{-1}$ down to $3 \mathrm{~m}^{2} \mathrm{~g}^{-1}$. Concomitantly, the oxygen content is divided by a factor of five. A set of $\mathrm{VO}_{x} \mathrm{~N}_{y}$ powders was synthesized within the same range of BET surface area. These values are in good agreement with previous synthesis of $\mathrm{VO}_{\mathrm{x}} \mathrm{N}_{\mathrm{y}}$ powders using oxide precursors which exhibit surface areas ranging from 23 to $57 \mathrm{~m}^{2} \mathrm{~g}^{-1}$ [18,19]. A different synthesis route of vanadium nitride powder, leading to $\mathrm{VN}_{1.08} \mathrm{O}_{0.36} \mathrm{Cl}_{0.1}$ composition only shows similar value of BET surface area (39 $\mathrm{m}^{2} \mathrm{~g}^{-1}$ [16]).

(a)

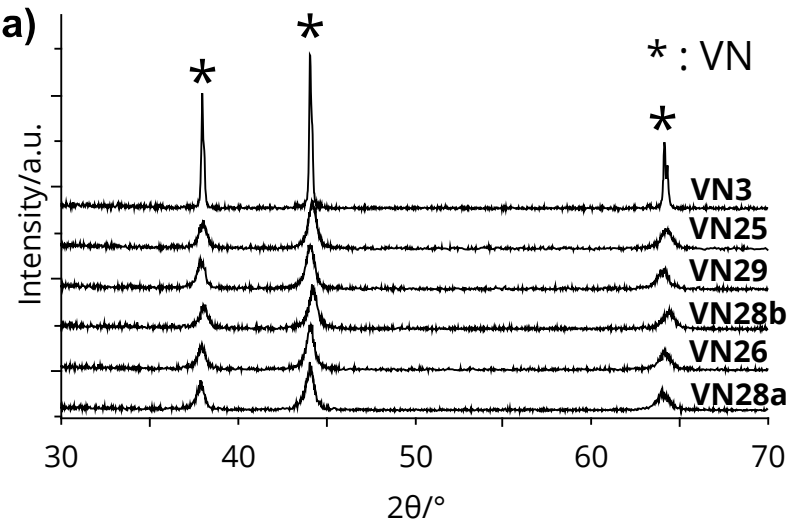

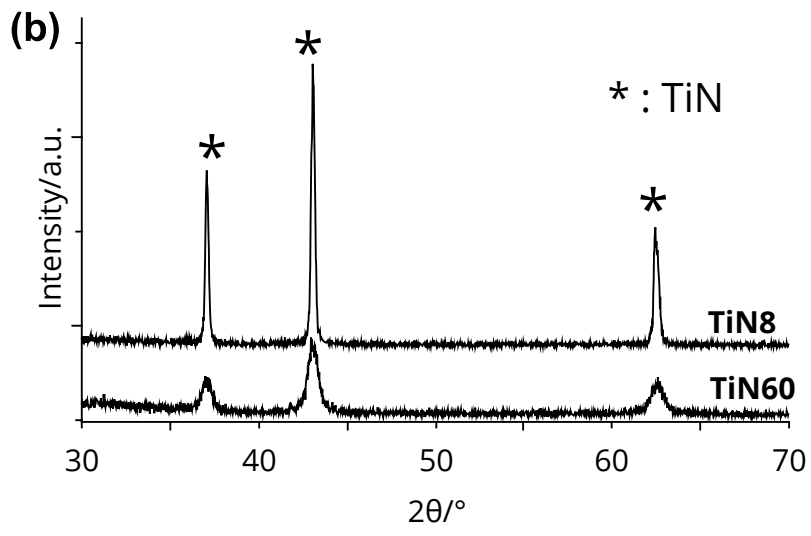

Fig. 1. X-ray diffraction powder patterns of (a) VN (oxy)nitrides (VN3, VN26, VN25, VN28a, VN28b, and VN29), and (b) TiN samples (TiN8 and TiN60). 
The same synthesis strategies have been applied to the preparation of TiN powders, but those tested as electrochemical capacitor electrodes have been prepared using oxygen free precursors. Janes et al. [15] reported that metathesis reaction between $\mathrm{TiCl}_{3}$ and $\mathrm{Ca}_{3} \mathrm{~N}_{2}$ produces phase-pure titanium nitride after washing away the $\mathrm{CaCl}_{2}$ byproduct. TiN was also obtained by a two-step halide approach consisting in a room-temperature $\mathrm{TiCl}_{4}(\mathrm{l})-\mathrm{NH}_{3}(\mathrm{~g})$ reaction followed by heat-treatment under $\mathrm{NH}_{3}$ atmosphere [14]. Although the chemical compositions of the samples apparently do not show oxygen content, the synthesis setups are not quite easy to achieve. In our case, commercially available $\mathrm{TiO}_{2}$ precursor is used and annealing treatment under $\mathrm{NH}_{3}$ is efficient for preparing cubic TiN (Fm-3m) crystallographic phase (Fig. 1a) with a cell parameter in agreement with that expected $(\approx 0.423 \mathrm{~nm})$. As for VN, our synthesis method can tune the oxygen content and BET surface area by adjusting annealing time and temperature. Samples with BET surface area from 8 to $60 \mathrm{~m}^{2} \mathrm{~g}^{-1}$ have been prepared. However, this increase is concomitant with the increase of oxygen in the powder which nearly reaches half of the nitrogen content in the high surface area powder. In the literature, the data also show quite impressive values of BET surface area (up to $128 \mathrm{~m}^{2} \mathrm{~g}^{-1}$ [16]) with chlorine in the powder composition but apparently without introducing oxygen in the samples.
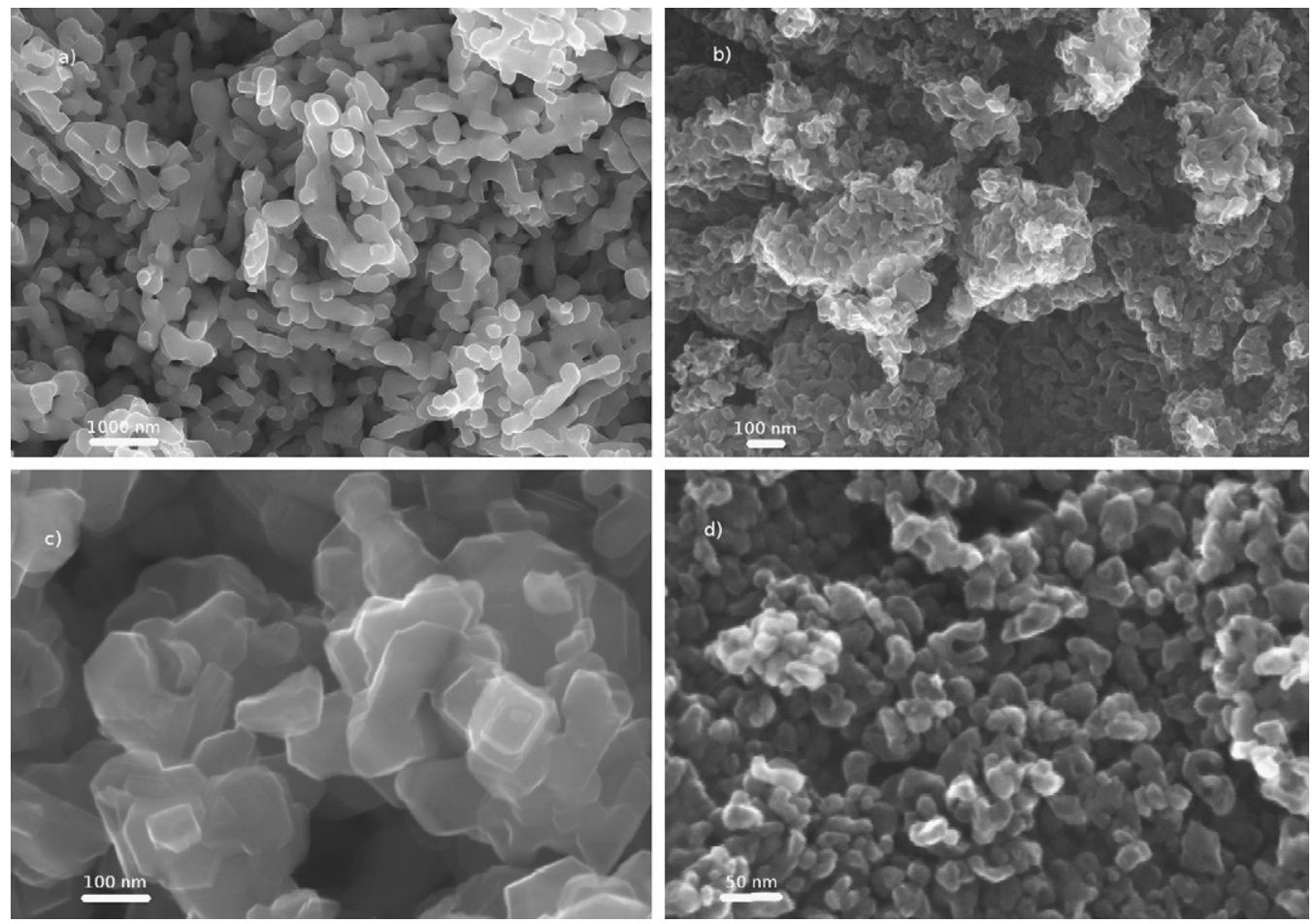

Fig. 2. Typical scanning electron micrographs of the VN and TiN powders. (a) VN3, (b) VN29, (c) TiN8 and (d) TiN60.

The morphology of $\mathrm{VO}_{\mathrm{x}} \mathrm{N}_{\mathrm{y}}$ and $\mathrm{TiO}_{\mathrm{x}} \mathrm{N}_{\mathrm{y}}$ powders (Fig. 2) are in good agreement with the reported values of BET surface areas. High temperature annealing treatment for the synthesis of $\mathrm{VO}_{x} \mathrm{~N}_{\mathrm{y}}$ powder (VN3, Fig. 2a) leads to spherical shaped grains with an average diameter of $350 \mathrm{~nm}$ which have already begin to sinter as depicted from the aggregates of 3 to 5 grains observed all over the sample. It can be noted that the calculated geometric surface area according to the average grain diameter $(350 \mathrm{~nm})$ and the density of $\mathrm{VN}\left(6.13 \mathrm{~g} \mathrm{~cm}^{-3}\right.$, although this value is not correct in this case, since $\mathrm{VO}_{\mathrm{x}} \mathrm{N}_{\mathrm{y}}$ were synthesized instead of pure $\mathrm{VN}$ ) gives a value close to $3 \mathrm{~m}^{2} \mathrm{~g}^{-1}$ in good agreement with the measured BET surface area, thus suggesting that the grains are not porous. VN29 powder (Fig. 2b) exhibits aggregates of smaller grains ( $\approx 30 \mathrm{~nm}$ diameter). Again the geometric surface area is in good agreement with the BET surface area, indicating porosity inside the aggregates but not inside the individual grains. The same remarks apply for $\mathrm{TiO}_{\mathrm{x}} \mathrm{N}_{\mathrm{y}}$ powders: TiN8 (Fig. 2c) and TiN60 (Fig. 2d) show different grain shapes and sizes which are also in good agreement with previously measured BET surface area.

From these SEM observations, it can be deduced that the synthesized powders have BET surface areas that are directly related to their grain size, i.e. implicitly to the annealing treatment that has been used for their synthesis, and furthermore only macroporosity arising from aggregates can be observed. The surface area is also very dependent on the starting oxide powder.

\subsection{Electrochemical characterizations}


Fig. 3 depicts the cyclic voltammograms of $\mathrm{VO}_{x} \mathrm{~N}_{y}$ and $\mathrm{TiO}_{\mathrm{x}} \mathrm{N}_{\mathrm{y}}$ based electrodes. The two nitrides show different active electrochemical window and different shapes of cyclic voltammograms (CVs). $\mathrm{VO}_{\mathrm{x}} \mathrm{N}_{\mathrm{y}}$ samples do not exhibit a typical pseudo-capacitive CV (Fig. 3a). Broad redox peaks can be observed and were already mentioned in previous studies [16-19]. Such a behavior is explained by the combination of electrical double layer formed by the hydroxyl ions adsorbed on non-specific sites wherein a large increase in specific capacitance arises primarily due to successive oxidation by the hydroxyl species on the $\mathrm{VO}_{\mathrm{x}} \mathrm{N}_{\mathrm{y}}$ surface due to electron transfer across the double layer [16] leading to $\mathrm{VO}_{\mathrm{x}} \mathrm{N}_{\mathrm{y}}-\mathrm{OH}$ species. This assumption was supported by various analytical techniques such as FTIR or XPS. Thus, it is believed that the electrochemical stability of $\mathrm{VO}_{\mathrm{x}} \mathrm{N}_{\mathrm{y}}$ in $\mathrm{KOH}$ electrolyte will be strongly dependent upon the lower and upper potential limits of the electrochemical window. In our case we were not able to detect by XPS experiments, neither by FTIR, specific changes in the powder electrodes polarized at the lower and upper potential limits, respectively. It is difficult from the CVs to assign redox peaks to specific redox reactions. It can be noted that even if the two $\mathrm{VO}_{\mathrm{x}} \mathrm{N}_{\mathrm{y}}$ powders exhibit close values of BET surface area $\left(25\right.$ and $\left.29 \mathrm{~m}^{2} \mathrm{~g}^{-1}\right)$ the coulombic charge calculated from the current integration is somehow different for the two samples.
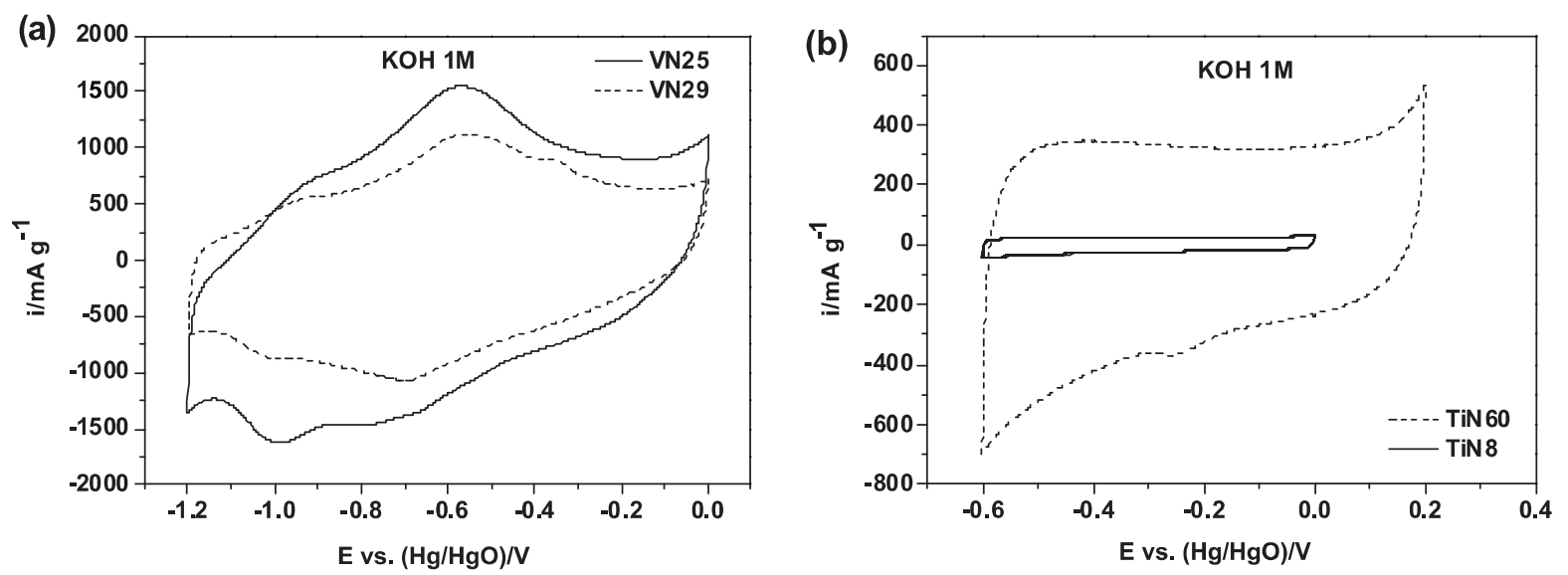

Fig. 3. Cyclic voltammograms of (a) VN25 (solid line) and VN-29 (dash line) in KOH $1 \mathrm{M}^{2} 10 \mathrm{mV} \mathrm{s}^{-1}$, and (b) TiN8 (solid line) and TiN60 (dash line) with different potential windows in $\mathrm{KOH} 1 \mathrm{M}$ at $10 \mathrm{mV} \mathrm{s}^{-1}$.

Unlike VN electrochemical CV signature, the CV of TiN powder electrode looks like a carbon electrode CV in aqueous media [24,25]. Small bumps can be observed and electroactive potential window is limited at $0.8 \mathrm{~V}$ as a maximum (Fig. 3b). This behavior is quite similar to the one reported by Choi et al. [16]. As the BET surface area of the electrode increases, the area of the CV increases. Current density values are less interesting than for VN electrodes and the lack of visible redox reaction can be an explanation.

\section{Discussion}

The set of $\mathrm{VO}_{\mathrm{x}} \mathrm{N}_{\mathrm{y}}$ and $\mathrm{TiO}_{\mathrm{x}} \mathrm{N}_{\mathrm{y}}$ powders prepared with simple $\mathrm{NH}_{3}$ annealing technique allowed us to investigate the influence of the surface area and of the oxygen content on the capacitance of the electrodes. Fig. 4a depicts the dependence of capacitance with the variation of the surface area. From this plot it can be evidenced a strong dependence of the two parameters. However, samples with almost the same surface area result in a similar capacitance value. An average slope of $\approx 0.3 \mathrm{mF} \mathrm{cm}^{-2}$ is calculated from the set of data of $\mathrm{VO}_{\mathrm{x}} \mathrm{N}_{\mathrm{y}}$ electrodes. This value drops down to $0.05 \mathrm{mF} \mathrm{cm}^{-2}$ for $\mathrm{TiO}_{\mathrm{x}} \mathrm{N}_{\mathrm{y}}$ electrode. This is in good agreement with the discrepancies previously reported for the $\mathrm{CV}$ shapes. Indeed, a capacitance of $50 \mu \mathrm{F} \mathrm{cm}{ }^{-2}$ as observed for $\mathrm{TiO}_{x} \mathrm{~N}_{\mathrm{y}}$ can be related to pure double layer capacitance since it is in the range of those observed for metals [26]. A faradic contribution can also be envisioned but it might be difficult to discriminate from the electrochemical measurements. However, a simple calculation taking into account the amount of charges stored at the surface of the electrode $\left(50 \mu \mathrm{F} \mathrm{cm}^{-2-} \times 0.8 \mathrm{~V}=40 \mu \mathrm{C} \mathrm{cm}^{-2}\right)$ indicates that if the charge storage mechanism was purely faradic, less than $0.4 \AA$ of the surface of $\mathrm{TiO}_{\mathrm{x}} \mathrm{N}_{\mathrm{y}}$ particles would be involved according to the theoretical density of $\operatorname{TiN}\left(5.25 \mathrm{~g} \mathrm{~cm}^{-3}\right)$. Thus, it is quite clear that either double layer capacitance is the main charge storage mechanism, or faradic reactions strictly located at the surface of $\mathrm{TiO}_{\mathrm{x}} \mathrm{N}_{\mathrm{y}}$ particles are responsible for charge storage. Similar values $\left(70 \mu \mathrm{F} \mathrm{cm}^{-2}\right)$ are also reported in the literature for TiN electrodes [14]. 

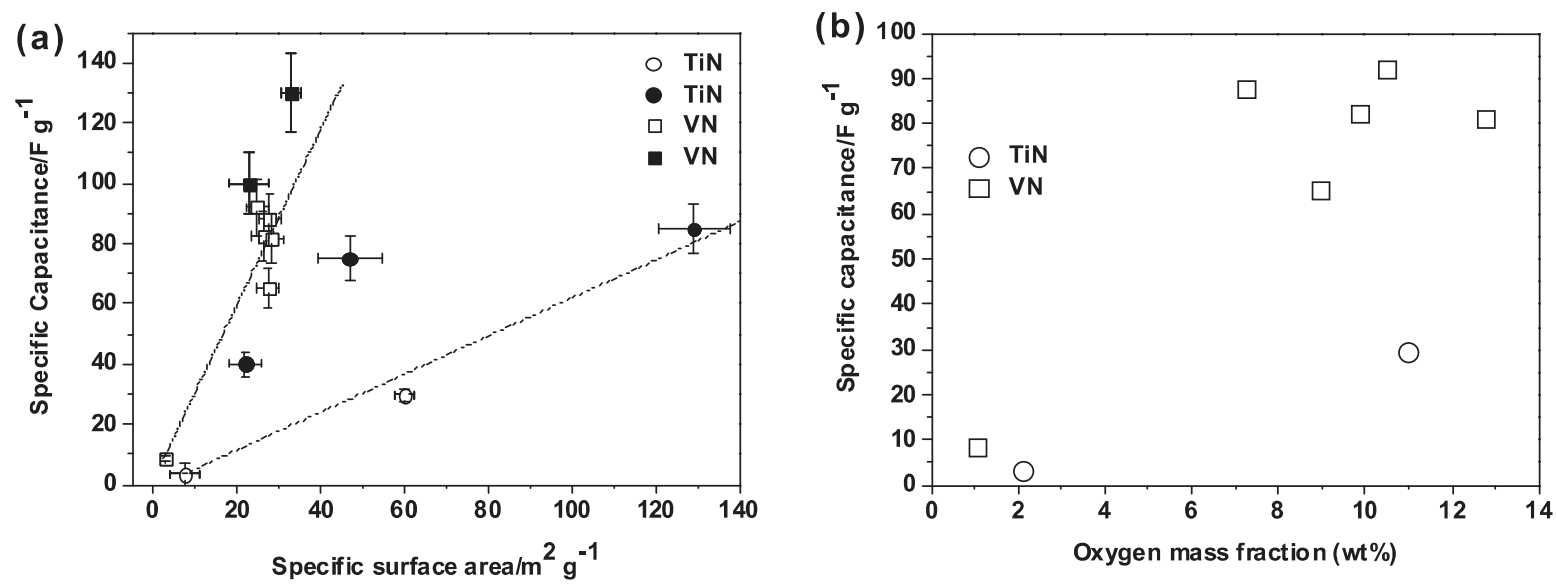

Fig. 4. Specific capacitance of VN and TiN powders (a) as a function of specific surface area (BET); open symbols = our samples, plain symbols = data extracted from Refs. [14-22] (lines are guidelines for the eyes); (b) as a function of oxygen mass fraction in $\mathrm{KOH} 1 \mathrm{M}$ at $20 \mathrm{mV} \mathrm{s}^{-1}$.

Since $\mathrm{VO}_{\mathrm{x}} \mathrm{N}_{\mathrm{y}}$ electrodes exhibit a charge stored of $360 \mu \mathrm{C} \mathrm{cm}{ }^{-2}$, i.e. 7 times higher than for TiN electrodes, the same calculation leads to a layer of $\approx 4 \AA$ affected by charge storage, based on a one electron process (which can be a two electron process for $\mathrm{VN}$ ). This represents nearly one elementary cell, thus indicating that in the case of $\mathrm{VO}_{\mathrm{x}} \mathrm{N}_{\mathrm{y}}$ oxidized species can formed within a thin but significant layer below the surface of the oxynitride particles. Unlike pure vanadium nitride which shows an compact cubic structure with not so much space for oxygen or hydroxyl diffusion, oxynitrides exhibits a much less dense structure probably partially responsible for fast redox reactions and long term cycling ability. Similar values of surface capacitance are found in different papers [16-19]. This also explains the larger capacitance values reported in the literature for VN electrodes compared to TiN electrodes. In our case, at $2 \mathrm{mV} \mathrm{s}^{-1}$, the maximum capacitance value was $105 \mathrm{~F} \mathrm{~g}^{-1}$ instead of $1340 \mathrm{~F} \mathrm{~g}^{-1}$ as reported by Choi et al. [16]. However, the active material loading in our electrodes is $\approx 20 \mathrm{mg} \mathrm{cm}^{-2}$, i.e. 100 times that of Choi's electrodes, which might explain partly this discrepancy. To support this assumption, literature data extracted from Refs. [14-22] have been plotted in Fig. 4a (plain symbols). We have only plotted the data corresponding to active material loading $>2 \mathrm{mg} \mathrm{cm}^{-2}$ in the electrode, which is however 10 times lower than the loading in our electrodes. Obviously, the values obtained on oxynitride powders $\mathrm{TiO}_{x} \mathrm{~N}_{y}$ and $\mathrm{VO}_{\mathrm{x}} \mathrm{N}_{\mathrm{y}}$ are in very good agreement with those already reported, thus confirming the difference of slopes for titanium and vanadium oxynitrides. The impressive value reported by Choi et al. [16] corresponds to a much lower loading, $0.25 \mathrm{mg} \mathrm{cm}^{-2}$, i.e. 80 times less than for our electrodes. From our previous experience on $\mathrm{MnO}_{2}$ electrodes for ECs [27], and from similar literature report [28], such small loading leads to unusually high capacitance values. This phenomenon is interesting to investigate but it is difficult to extrapolate capacitance values for such small amount of powder when used in a real life device. This is discussed in details in a recent paper from Gogotsi and Simon [29]. We believe the values measured for vanadium and titanium oxynitride powders correctly reflects the performance of these materials in a future device and this point is discussed at the end of this section. When used in a composite electrode with binder and carbon additive, the capacitance of $\mathrm{TiO}_{x} \mathrm{~N}_{\mathrm{y}}$ and $\mathrm{VO}_{\mathrm{x}} \mathrm{N}_{\mathrm{y}}$ based electrodes strongly relies upon the surface area of the powders. Since with our synthesis method links the surface area and the oxygen content we also investigated this point.

Fig. 4b tries to establish a relationship between oxygen content and capacitance. The plot does not provide any clear trend. Above a certain weight ratio (10\%), the capacitance does not seem to show any further increase. This may be due either to a limitation of the electronic conductivity when the oxygen content increases too much in the samples or to a loss of surface active redox sites. Additional data need to be implemented before giving a definite answer. However, this plot again points out the possible use of oxynitrides instead of pure nitride powders as electrodes for Ecs. 


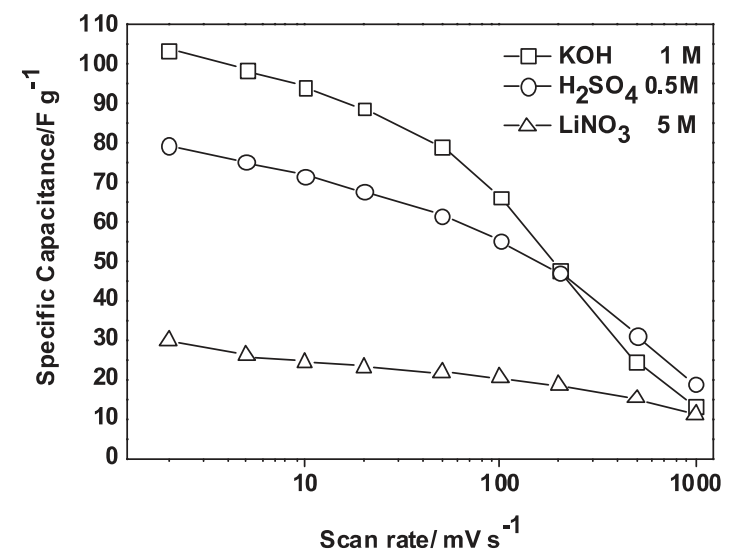

Fig. 5. Specific capacitance of VN29 as a function of the scan rate in different electrolytes.

According to these results we focus our interest on $\mathrm{VO}_{\mathrm{x}} \mathrm{N}_{\mathrm{y}}$ electrodes that have already demonstrated quite impressive capacitance values [16]. Fig. 5 shows the power capability of VN29 electrode which has the largest surface area among all the $\mathrm{VO}_{\mathrm{x}} \mathrm{N}_{\mathrm{y}}$ synthesized powders. The highest capacitance values are measured in $1 \mathrm{M} \mathrm{KOH}$ compared to the values measured in acidic $\left(\mathrm{H}_{2} \mathrm{SO}_{4}\right)$ or neutral $\left(\mathrm{LiNO}_{3}\right)$ electrolytes. In this last case, the capacitance value is less than $30 \%$ of that measured in $\mathrm{KOH}$ electrolyte, again suggesting the role of hydroxyl species for successive oxidation on the $\mathrm{VO}_{\mathrm{x}} \mathrm{N}_{\mathrm{y}}$ surface. Similar drop in capacitance was also measured for other neutral electrolytes $\left(\mathrm{Na}_{2} \mathrm{SO}_{4}, \mathrm{~K}_{2} \mathrm{SO}_{4}\right)$. Unlike what is occurring to $\mathrm{VO}_{\mathrm{x}} \mathrm{N}_{\mathrm{y}}$ electrode in $\mathrm{KOH}$ or $\mathrm{H}_{2} \mathrm{SO}_{4}$ electrolytes, the capacitance of $\mathrm{VO}_{\mathrm{x}} \mathrm{N}_{\mathrm{y}}$ electrode in $\mathrm{LiNO}_{3}$ is quite stable even at fast cycling rates $\left(1 \mathrm{~V} \mathrm{~s}^{-1}\right)$. It might be related to double layer capacitance in this case $\left(\approx 10 \mu \mathrm{F} \mathrm{cm}^{-2}\right)$, coupled with the good electronic conductivity of the electrode which provides almost the same behavior as for carbon based electrodes. At $1 \mathrm{~V} \mathrm{~s}^{-1}$ acidic or basic media leads to exactly the same capacitance value as in $\mathrm{LiNO}_{3}$. According to Trassatti et al. [30], at high scan rates only the surface charge is measured. Subsequently, at low scan rate $\left(2 \mathrm{mV} \mathrm{s}^{-1}\right)$ if the capacitance in $\mathrm{LiNO}_{3}$ electrolyte is only due to double layer capacitance, the same contribution applies to $\mathrm{KOH}$ electrolyte thus resulting in $70 \%$ of the capacitance coming from redox reactions occurring within a thickness of few angstroms as calculated before. Such a thin layer should promote the cycling ability compared to bulk redox reactions. It can be noted that the behaviors described above at slow and fast scan rates are strongly dependant on the electrode formulation (dispersion of binder, of carbon additive, remaining porosity, etc.). Thus the electrochemical measurements reflect the performance of a composite electrode and not the intrinsic value of the electroactive materials. This is the main reason why no further deductions are extrapolated from Fig. 5. Ongoing studies on vanadium and titanium nitride thin films aim at determining the intrinsic behavior of these materials, coupling electrochemical techniques such as electrochemical impedance spectroscopy to different spectrometric methods. In Fig. 6, the cycling ability of VN29 electrode has been investigated. The fade of capacitance upon cycling is strongly dependent upon the electrochemical window used for the electrochemical tests. A large window $(-1.2 \mathrm{~V}$ up to $0 \mathrm{~V}$ vs $\mathrm{Hg} / \mathrm{HgO})$ is detrimental to the stability of the electrode. When the window is limited below $-0.4 \mathrm{~V}$ for the upper potential cut-off limit, the cycling ability is greatly improved. This is probably due to the prevention of electrode oxidation and the concomitant formation of soluble vanadium based species when a too high potential limit is used. This was reported in a similar way by Choi et al. [16]. Restricting the potential window increases the cycling stability but the electrode still loses $30 \%$ of its starting capacitance after 2800 cycles. The small electrochemical window is probably also a main limitation for the assembly of a symmetrical device using vanadium oxynitride as positive and negative electrodes. Indeed, with a cell voltage limited to $0.8 \mathrm{~V}$, the energy density will be severely restricted. The energy density varies as the square of the maximum cell voltage which is close to $2.7 \mathrm{~V}$ for symmetrical activated carbon commercial ECs. Subsequently, in a symmetrical device, from a gravimetric point of view the capacitance of vanadium oxynitride electrode has to be more than 10 times that of an activated carbon electrode (i.e. about $1000 \mathrm{~F} \mathrm{~g}^{-1}$ ) to compensate for lower cell voltage. The present study shows that such capacitance value is quite difficult to achieve with standard composite electrode using a loading of $\approx 10 \mathrm{mg} \mathrm{cm}{ }^{-2}$. Alternatively, asymmetric designs can be achieved, using vanadium oxynitride as negative electrode and a complementary electrode based on cobalt or nickel oxides in $\mathrm{KOH}$ electrolyte for example. 


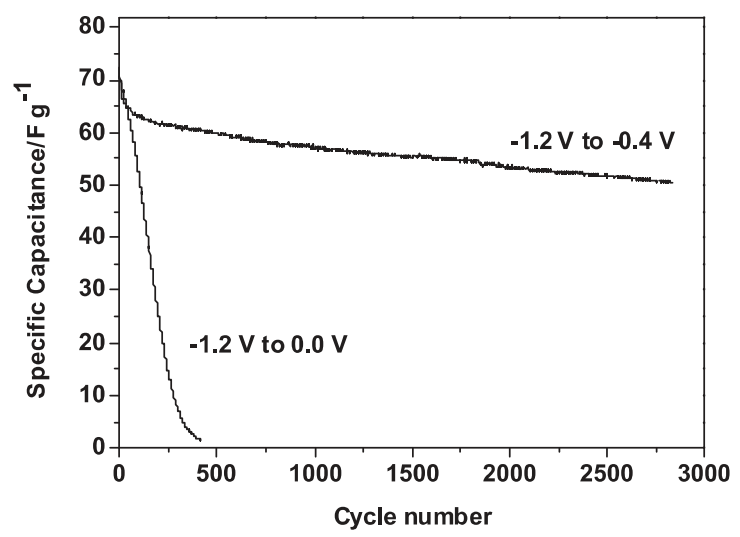

Fig. 6. Specific capacitance of VN29 as a function of cycling number. The black line indicates the behavior of VN29 upon cycling with a potential window from -1.2 to $0.0 \mathrm{~V}$ vs $\mathrm{Hg} / \mathrm{HgO}$ and the bold black line from -1.2 to $-0.4 \mathrm{~V} \mathrm{vs} \mathrm{Hg} / \mathrm{HgO}$. The cycling test was performed in $\mathrm{KOH} 1 \mathrm{M}$ at $20 \mathrm{mV} \mathrm{s}^{-1}$.

\section{Conclusions}

A versatile nitridation technique has been used to synthesize $\mathrm{TiO}_{x} \mathrm{~N}_{\mathrm{y}}$ and $\mathrm{VO}_{\mathrm{x}} \mathrm{N}_{\mathrm{y}}$ powders with controlled oxygen content and surface area. The electrochemical performances of the different powders have been investigated. For vanadium and titanium based powders the capacitance is linearly related to the surface area while no obvious relationship has been found with the oxygen content. $\mathrm{VO}_{\mathrm{x}} \mathrm{N}_{\mathrm{y}}$ powders exhibit surface redox reactions restricted in the vicinity of the surface of the electrode (few angstroms below the surface). $\mathrm{TiO}_{\mathrm{x}} \mathrm{N}_{\mathrm{y}}$ powders show a different behavior with typical pseudocapacitve signature and charge storage mechanism compatible with double layer capacitance values observed for carbons or some metals. Thus it is not surprising that the capacitance values are higher for vanadium based oxynitride powders. However, efforts need to be made to increase power capability of $\mathrm{VO}_{\mathrm{x}} \mathrm{N}_{\mathrm{y}}$ electrodes as well as their cycling ability which depends on the electrochemical window used for electrochemical measurements. Such powders are attractive due to their interesting density $\left(\approx 6 \mathrm{~g} \mathrm{~cm}^{-3}\right)$, about 10 times that of activated carbon, and their good stability in different aqueous based electrolytes, from acidic to strongly basic $\mathrm{pH}$. However, designing ECs with such materials will require the use of asymmetric device in order to keep an attractive cell voltage.

\section{Acknowledgement}

This work was supported by French ANR-STOCK E 2009, within the framework of Advanced NiBaCa project.

\section{References}

[1] B.E. Conway, Electrochemical Supercapacitors, Kluwer Academic/Plenum Publishers, New York, 1999.

[2] K. Naoi, P. Simon, Electrochemical Society Interface 17 (2008) 33.

[3] S. Trasatti, G. Buzzanca, Journal of Electroanalytical Chemistry 29 (1971) A1.

[4] J.P. Zheng, P.J. Cyang, T.R. Jow, Journal of the Electrochemical Society 142 (1995) 2699.

[5] H.Y. Lee, J.B. Goodenough, Journal of Solid State Chemistry 144 (1999) 220.

[6] S.C. Pang, M.A. Anderson, T.W. Chapman, Journal of the Electrochemical Society 147 (2000) 444.

[7] J.W. Long, K.E. Swider-Lyons, R.M. Stroud, D.R. Rolison, Electrochemical and Solid State Letters 3 (2000) 453.

[8] M. Toupin, T. Brousse, D. Bélanger, Chemistry of Materials 14 (2002) 3946.

[9] D. Bélanger, T. Brousse, J.W. Long, Electrochemical Society Interface 17 (2008) 49.

[10] W. Wei, X. Cui, W. Chen, D.G. Ivey, Chemical Society Reviews 40 (2011) 1697.

[11] J.W. Long, D. Bélanger, T. Brousse, W. Sugimoto, M.B. Sassin, O. Crosnier, MRS Bulletin 36 (2011) 513.

[12] C. Liu, W.G. Pell, B.E. Conway, L.S. Roberson, Journal of the Electrochemical Society 145 (1998) 1882.

[13] S.L. Roberson, D. Finello, R.F. Davis, Journal of Applied Electrochemistry 29 (1999) 75.

[14] D. Choi, P.N. Kumta, Journal of the Electrochemical Society 153 (2006) A2298.

[15] R.A. Janes, M. Aldissi, R.B. Kaner, Chemistry of Materials 15 (2003) 4431.

[16] D. Choi, G.E. Blomgren, P.N. Kumta, Advanced Materials 18 (2006) 1178.

[17] X. Zhou, H. Chen, D. Shu, C. He, J. Nan, Journal of Physics and Chemistry of Solids 70 (2009) 495.

[18] A.M. Glushenkov, D. Hulicova-Jurcakova, D. Llewellyn, G.Q. Lu, Y. Chen, Chemistry of Materials 22 (2010) 914.

[19] F. Cheng, C. He, D. Shua, H. Chen, J. Zhang, S. Tang, D.E. Finlow, Materials Chemistry and Physics 131 (2011) 268.

[20] C.M. Ghimbeu, E. Raymundo-Piñero, P. Fioux, F. Béguin, C. Vix-Guterl, Journal of Materials Chemistry 21 (2011) 13268. 
[21] S. Dong, X. Chen, L. Gu, X. Zhou, H. Wang, Z. Liu, P. Han, J. Yao, L. Wang, G. Cui, L. Chen, Materials Research Bulletin 46 (2011) 835.

[22] D. Choi, P.N. Kumta, Journal of the American Ceramic Society 94 (2011) 2371.

[23] F. Tessier, R. Marchand, Journal of Solid State Chemistry 171 (2003) 143.

[24] T. Brousse, M. Toupin, D. Bélanger, Journal of the Electrochemical Society 151 (2004) A614.

[25] M. Toupin, D. Bélanger, I. Hill, D. Quinn, Journal of Power Sources 140 (2005) 203.

[26] S. Trasatti, Journal of Electroanalytical Chemistry 123 (1981) 121.

[27] M. Toupin, T. Brousse, D. Bélanger, Chemistry of Materials 16 (2004) 3184.

[28] A. Cross, A. Morel, J.A. Cormie, T. Hollenkamp, S.W. Donne, Journal of Power Sources 196 (2011) 7847.

[29] Y. Gogotsi, P. Simon, Science 334 (2011) 917.

[30] S. Ardizzone, G. Fregonara, S. Trasatti, Electrochimica Acta 35 (1990) 263. 